\title{
Feasibility Study of the Soil Remediation Technologies in the Natural Environment
}

\author{
Mithun Chakrabartty, Gazi Mohammad Harun-Or-Rashid* \\ Department of Civil Engineering, Rajshahi University of Engineering \& Technology, Rajshahi, Bangladesh \\ Email address: \\ mithun.ruetce@gmail.com (M. Chakrabartty),gmharun.ruet11@gmail.com (G. M. Harun-Or-Rashid) \\ ${ }^{*}$ Corresponding author
}

\section{To cite this article:}

Mithun Chakrabartty, Gazi Mohammad Harun-Or-Rashid. Feasibility Study of the Soil Remediation Technologies in the Natural Environment. American Journal of Civil Engineering. Vol. 9, No. 4, 2021, pp. 91-98. doi: 10.11648/j.ajce.20210904.11

Received: June 18, 2021; Accepted: July 2, 2021; Published: July 22, 2021

\begin{abstract}
Today's world is dependent on industrialization and without it the economic development of a country can hardly be considered. Therefore the rapid increase of industries around the world has upgraded the human life. But this industrialization has some impact of environment causing pollution. Industrial waste disposal, use of excessive fertilizer and other natural and human activities causes soil pollution, which is burning question nowadays. To protect environment and human beings from the bad effect of soil contamination is a great issue. This article focused on several remediation techniques for the removal of contaminants (hydrocarbons like- petroleum and fuel residues, heavy metals, pesticides, volatiles or semivolatiles) from soil in situ and ex situ and their properties and applications. In this research it is tried to uncover the real scenario of the soil remediation technology. This remediation technology are classified as- physical, chemical, biological, thermal, and combined. For the selection of most suitable technique various factors are needed to be considered. Besides that, the research has discussed the advantages and drawbacks of each remediation techniques. It was observed that the efficiency of any single remediation technique is not well enough for the complete removal of all contaminants from soil whereas combination of remediation techniques brings better efficiency for soil purification.
\end{abstract}

Keywords: Soil Contaminants, Remediation Techniques, In Situ, Technique Selection, Combination of Techniques

\section{Introduction}

Contamination of environment is associated with the development of modern society. Soil is one of the most important components of environment because of a role in plants growths, degradation of biomass. The contamination of soils is a burning environmental issue of human health and food production, and this is owing to the presence of many polluted sites and of excess concentration of chemicals which causes health risks. Soil contamination causes loss not only land as a resource but also property. Air contamination inside residential structures, contamination of farm vegetables and animals, and increasing risk in digging are the some other effects of soil contamination. So, there is a huge possibility of being harmed of the people who are surrounded by the contaminated soil around their houses, offices, schools, parks and the places where the public gather to perform their daily activities.

Soil can be contaminated in various ways like: industrial waste disposal, mining areas, agricultural activities and domestic waste disposal etc. Existence of heavy metals in soil layers, their adverse toxic effect is responsible to soil contamination. Beside metals, organic contaminants are most often found in soils and sediments, and the untreated organic contaminants may mix up with the groundwater [16]. Other inorganic contaminants like metals such as $\mathrm{Ag}, \mathrm{Al}, \mathrm{As}, \mathrm{Be}$, $\mathrm{Cd}, \mathrm{Cr}, \mathrm{Cu}, \mathrm{Hg}, \mathrm{Fe}, \mathrm{Ni}, \mathrm{Pb}, \mathrm{Sb}, \mathrm{Se}, \mathrm{Zn}$, and radioactive elements are responsible for contamination [17]. Running or past industrial activities, products by the inhabitants, automobile emissions can contaminate soil of the urban areas. These activities harm human when they come in contact with contaminated soil, it harm the organism of soil as well. Some other specific reason of soil contamination are- tanks leakage or defect in operations, faulty preservation of products or wastes, sewerage pollutants, and excessive use of pesticides and fertilizer in the field. Humans are also accountable for contaminating soil, because they dump some severe compound in the soil (like- heavy metals, volatile compounds, 
and semi-volatile compounds). Therefore environment contamination remediation procedures are to be applied in order to protect human health as well as environment. Environment contamination remediation procedures comprises of cleanup, diminish, correct, minimize, abolish, manage and prevent the contaminant discharge into the environment which includes actions to inspect, study and assess the actual or possible discharge.

A number of researchers are conducted to find out the remediation of contaminated soil. Faisal et al., (2004) worked on soil contaminated by hydrocarbon products and reviewed the analysis of this site remediation technologies [11]. Ralph et al., (2006) analyzed the thermal remediation techniques for in situ contaminated soil and resulted that thermal remediation is good enough for redevelopment and containing heterogeneous soil and remediation of sites with access restrictions [26]. Mitchell and Thomas (2012) research to valuated the in situ thermal remediation technologies which evaluated that thermal extraction is a feasible technology which can facilitate and clean up at many contaminated sites despite the failure of traditional extraction technologies [20]. Mohammad et al., (2008) worked on phytoremediation for the soil and water contaminated with heavy metals [21]. The outcome of that work guided a review of phytoremediation on current progresses in research and practical application. Raymond and Felix (2011) found some important factors like-the sources, chemistry, feasibility and appropriate procedures for heavy metals removal from contaminated soil [27]. Paulo et al., (2014) worked for the phytoremediation of metals and metalloids contaminated soil at mining areas [25]. Suthersan (1999) found a variations among the sites (worked on in situ) where air sparging has been used to remediate contaminated soil [29].

Contaminated soil intensity and nature are changing continually with the passing time. Therefore new challenges are coming to be faced off. Now it is the today's demand to face this challenges through advance and more effective techniques. Focusing on the remediation techniques some researchers paid extra attention of the following decisions. Firstly, a thorough study has to done on the contamination coverage and all possible alternative remediation techniques. Secondly, emphasizing on the following factors likeenvironmental, related techniques and the economic factors the suitable remediation technique should be selected. Thirdly, finishing decision of the remediation activities have to be made [6]. The main research theme of this research is to analyze the available technologies for contaminated soil remediation in natural environment and finding out a most appropriate technique.

\section{Classification of the Soil Remediation Technology}

Mainly there are two types of technology for the remediation of contaminated soil or contaminated areas according to the location: in-situ technologies and ex-situ technologies. The treatment of the contaminated soil is carried out at the location of its origin, is known as in situ remediation technique. In this technique the contaminants can be removed from the soil or sediment in the contaminated areas without replacing it. Whereas the treatment of the contaminated soil carries out in other location except its origin, is known as ex-situ technologies. In-situ technologies do not require excavation of the contaminated area for the treatment can be classified into the following categories-

(a) Biological treatment: Enhanced Bioremediation, Phytoremediation

(b) Physical/Chemical Treatment: Chemical Oxidation, Electrokinetic Separation (ER), Soil Flushing, Soil Vapor Extraction, Solidification/Stabilization (S/S)

(c) Thermal Treatment: Thermal Treatment

In ex-situ technology the treatment requires excavation of the contaminated soils. Beside this, contaminated soil is disposed other site after treatment and backfilling carried out with uncontaminated soil. The ex-situ technologies (assuming excavation) can be classified as follows-

(a) Biological Treatment: Biopile Treatment, Slurry Phase Biological Treatment

(b) Physical/Chemical Treatment: Chemical Extraction, Dehalogenation, Separation, Soil Washing, Solidification/Stabilization

(c) Thermal Treatment: Hot Gas Decontamination, Incineration Pyrolysis, Thermal Desorption

The soil which is contaminated heavily requires a combination of remediation technique. There are some guiding factors that influence the selection and application of appropriate remediation technologies are: workability to higher metal concentration, durability of efficiency and performance, expenditure, commercial availability, workability in different waste sand reduction of volume, mobility, and toxicity [27]. In this research especially those technologies are to be discussed which are possible in natural environment.

\section{Different soil Remediation Technologies}

\subsection{Surface Capping}

Surface capping is a simple technique to reduce soil contamination. In this technique the contaminated area is surfaced with the materials of comparatively low permeability. This surfacing of the contaminated site hinders the passage or movement of contaminants in the soil which reduce the risk of contact with the people in the contaminated area. Isolation and confining the contaminated can be done in this capping technique by various ways like- creating a physical obstruction made of steel, finer particles as cement, bentonite and grout walls. Horizontal and vertical confinements reduce the permeability of waste or contaminated soil and enhance the bearing capacity of the contaminated soil as well. After the application of this 
technique the site can be used some purposes like- parking lots, garages because of its environmental functions losing.

\subsection{Encapsulation}

Encapsulation is a remedial technique nearly similar with the surface capping principles. The principle of this technique is forming a physical isolation and confining the contaminant. Low permeability caps, slurry walls, grouting method, or cutoff walls are used to isolate the contaminated soils in this technique. Beside that coverage with layers of low permeability (like- layers of synthetic textiles or clay caps) can applied to the contaminated area. These layers reduce the infiltration and percolation of the precipitation which stops leaching and migration of pollutants from the contaminated area and get mixed with groundwater [2]. Though the encapsulation technique restrains the contaminant from being spreading to the uncontaminated soil but this technique cannot separate the contaminants from soil grains [5]. So, this encapsulation technique has a risk in using the soil for agricultural production. Moreover the technique cannot be taken as any permanent remedy of contaminant because its efficiency decreases with the passes of time. Despites this, if the off-site disposal is practical and the whole procedure becomes economical encapsulation is a suitable alternative for caring human health and protecting the environment. Figure 1 shows the most common technique of the encapsulation using a reactive barrier (permeable and semipermeable). Here an impermeable barrier is constructed into the bed rock in the contaminated area.

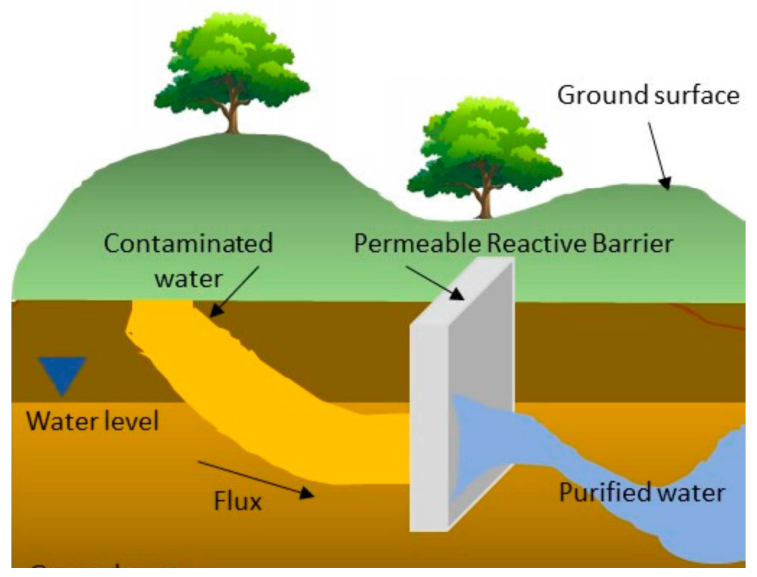

Figure 1. Scheme of Permeable Reactive Barriers [5].

\subsection{Soil Vapor Extraction (SVE)}

In-situ condition vapor extraction is useful technology to take away volatile contaminants (VOCs) and sub-volatile organic contaminants (SVOCs) from the contaminated soil, usually in unsaturated soils. It is also known as soil venting or vacuum extraction technique. The vapor pressure and solubility of the pollutants control the efficiency of the SVE technology. Some other factors which need to be evaluated for the application of SVE technique are- humidity, organic matter quantity, porosity, and soil permeability. This technique is also known as air sparging which is practical for the removal of vapors associated with the gas that helps in the volatilization or even degradation of contaminants in the groundwater [33].

Vertical and/or horizontal wells are installed in the contaminated soil areas and vapors are extracted in the SVE technique. A treatment (commonly carbon adsorption) of the extracted vapors is carried out before releasing these vapors into the atmosphere [30]. Biodegradation of Contaminants (especially less volatile) occurs due to the increasing of subsurface airflow in the SVE technique [31, 32].



Figure 2. Typical pipes transporting vapor from the underground SVE well to treatment [34].

Soil vapor extraction technique less time requires for remediation of contaminants (usually a few months to 2 years under optimal conditions) and it is an economical technique. It decreases volatile organic compounds (VOC) in the vadose zone of the contaminated soil, also reduces the possible migration of VOC $[30,11]$. Large volumes of soil can be treated with less site disturbance occurs in this SVE technique in spite of being in-situ technique. It possess less or no execution risk to the workers [31]. There are some limitations of SVE technique. High water content of soil reduces permeability and hampers the flowing of air through the soil voids/ pores which decreases the effectiveness to remove contaminant from soil of SVE technique [11, 30, 31]. Reduction of humidity of the soil enhance effectiveness of this technique [34]. In general, SVE applicability is limited to VOCs contaminated soil where the ground water table is low. Accurate of SVE remediation time prediction model is difficult to develop from the short -term collected data [3]. Fine grained soils are appropriate for SVE remediation technique [31, 32].

\subsection{Electrokinetic Remediation}

Electrokinetic remediation is a in-situ remediation technique to remove organic and inorganic contaminants from soil by electrical adsorption. In this remediation process a low-density electrical current is allowed to flow in the soil through electrodes which induces cations from the soil to the cathode and the anions to the anode through the established electrical field. The most favorable soil conditions are-saturated soil, partially saturated soil and low electric conductive soil or low salinity and cation exchange capacity [9]. Non-economic zone, military firing-grounds, left industrial areas is suitable for the application of this technology.

Electrokinetic technology can be applied for contaminated 
soils at non-accessible site for excavation can be treated. This technique is suitable for the soils of saturated zone and unsaturated zone also low hydraulic conductive soils (with high clay content) and inorganic contaminants can be treated with this technique. But soluble and desorption contaminant from the soil matrix can bound the effectiveness of the technology. Low ion concentration and high non-target ion concentration (background) may not be the favorable condition for the application of electrokinetic process. This technology requires the presence of conducting pore fluid to mobilize contaminants and the efficiency may be reduced if heterogeneous or anomalies like-submerged foundations, much iron or iron oxides, and rocks or gravels of large size are found in the site [9].

\subsection{Solidification and Stabilization}

Solidification process works as the process of encapsulation converting the contaminants in a monolithic solid of high structural integrity. The main technique of this technology is to prevent movement of the contaminants rather than removing them from the soil and converting the contaminant into less soluble and less toxic form, which can risk of waste soil.

Cement, asphalt, grey steering wheel and thermoplastics are the main components used for in the solidification technique. In-situ the cementing mud can be injected inside the soil at contaminated layer by high pressure or by bulldozer which blocks the pores of soil layer and reduces the permeability, limits movement of contaminants. The solidified matrix can be affected by weathering effect, which needed proper monitoring. Most used chemicals for the solidification process are- carbonates (lime), clay and minerals containing Iron (e.g. bauxite, goethite, silica gel, vermiculite and zeolites), phosphates (e.g. bone flour, ammonium phosphate, apatite and hydroxyapatite), alkaline agents (e.g. Ash flywheels and calcium hydroxide) and organic matter (e.g. chitosan, starch xanthate, peat, manure, activated charcoal and bio coal) [28]. Chemical agents used for the solidification process soil stimulate physic-chemical reactions with pollutants, forms precipitates, complex or absorbing them, decreases mobility.

In situ and ex situ Solidification process is more suitable for heavy metallic contaminants, radioactive contaminants, other inorganic compounds or highly toxic contaminants. At the same time, stabilization/ solidification technique is more feasible for the contaminated soil in which organic constituent's level is low and also feasible for volatile compounds [7]. In situ stabilization and solidification technique includes three main components: (1) a way to mixing the polluted soil in the site; (2) proper storage, preparation, and feed system of chemical reagent; and (3) a way to transport the prepared chemical reagents to the soil mixing site. Stabilization process possesses less efficiency against organics and pesticides, but efficiency is more for asphalt batching and vitrification because most organic contaminants are disinfected [10]. The treated soil by the stabilization/ solidification technique, has minimized ability to support plants and supporting micro-organisms in-situ.

\subsection{Soil Washing}

Soil washing is an ex-situ soil remediation technique to extract the contaminants from soil and environment. Aqueous solutions or liquids (usually water, occasionally combined with solvents) are used and mechanical processes to remove pollutants from soil forming an extraction solution [11]. In this process an aqueous solution is mixed with the excavated contaminated soil (ex-situ) for washing the soil and after treatment the clean soil can be replaced to its location of origin. This remediation process also can be applied as insitu (soil flushing), if washing solution can be mixed with soil through dug wells which soluble contaminants and form extraction solution [27]. This extraction solution must be collected and treated in surface before disposal. In-situ leaching of contaminated to the surrounded saturated area if the contaminated zone reaches the groundwater table and the groundwater should be treated. The selection of suitable solvents for contaminated soil washing depends on their ability to solubilize particular contaminants, affinity for the contaminants and their harmful effects on the environmental and health effects. In Soil washing technique hydrocarbon tends bind finer grains soil (clay and silt) and separates from coarse grains soil (sand and gravel) which reduces the volume of contaminated soil. This fine grained soil (clay and silt) volume can be disposed of in proper manner or can be treated by incineration or bioremediation. Besides the washed clean, larger volume of coarser soil grains can placed for backfilling as it is non-toxic [31]. Soil washing principle involves physical and chemical treatment to extract metal contaminants from soil [27]. Physical soil washing technique factors (like- particle grain size difference, settling velocity, specific gravity, surface chemical properties and magnetic behavior) are considered separate major accommodated particles from the contaminants exhausted particles. The treated clean soil particles are then separated to place of its origin and the contaminated aqueous solution is treated before disposal by some suitable means (like- sorption on activated carbon, ion exchange) [27]. This soil washing is capable to wash soil containing semi-volatile organic compounds (SVOCs), petroleum and fuel residuals, heavy metals, PCBs, PAHs, and pesticides [15] also can wash coarse -grained soils containing large quantity of organic and inorganic contaminants.

Soil washing technique produces recyclable material or energy are in most aspects, and its cleaning process is speedy hence can eliminate the contaminants. This technique provides short time liability [27]. Extracted water mixed with applied solution requires extra treated before its final disposal so this technique is cost-effective. Complex waste mixture need a blend of solvent and soil containing humic acids requires pretreatment in this technique [11]. With the application of organics adsorbed onto clay particles are not easy to eliminate and soil containing large amount of finer particles like- silt and clay is not effective for soil washing technique. 


\subsection{Bioventing or Bioventilation}

Bioventing is a technique for remediation of contaminated soil by introducing oxygen into the soil which enhances the growth of micro-organisms. This flowing of oxygen into the soil increases the microbial metabolism of organic contaminants, functioning as a substrate. The presence of oxygen in the soil enhances the biodegradation capacity and from the starting of metabolism it can accept electrons for power generation. The efficiency of this technique depends on the ease of air circulation through the soil, which is a function of the particle size and permeability of soil grains. The injection of uncontaminated water with dissolved oxygen enhance the effectiveness of this technique [4]. The installation of oxygen injection facilities depend on some factors like- soil gas permeability, pollutant dispersal and distribution and environmental factors (such as $\mathrm{pH}$, water content, and temperature and electron receiver condition) [33]. For saturated soil bioventing the elapsed time is less and do not require any extra treatment of the off gas. So, this method can be combined easily with some other remediation technology and low clean up time cannot be reached every time [11].

Bioventing technique introduces oxygen/ air only into the unsaturated or vadose zone, where biosparging method also involves introducing air and nutrients into the saturated zone [32]. In bioventing process is able to degrade small quantity of volatile organic contaminants because it supplies more air, it applicable for low permeable soils in-situ condition [10]. A simplified sketch bioventing process is shown in figure 3 below-

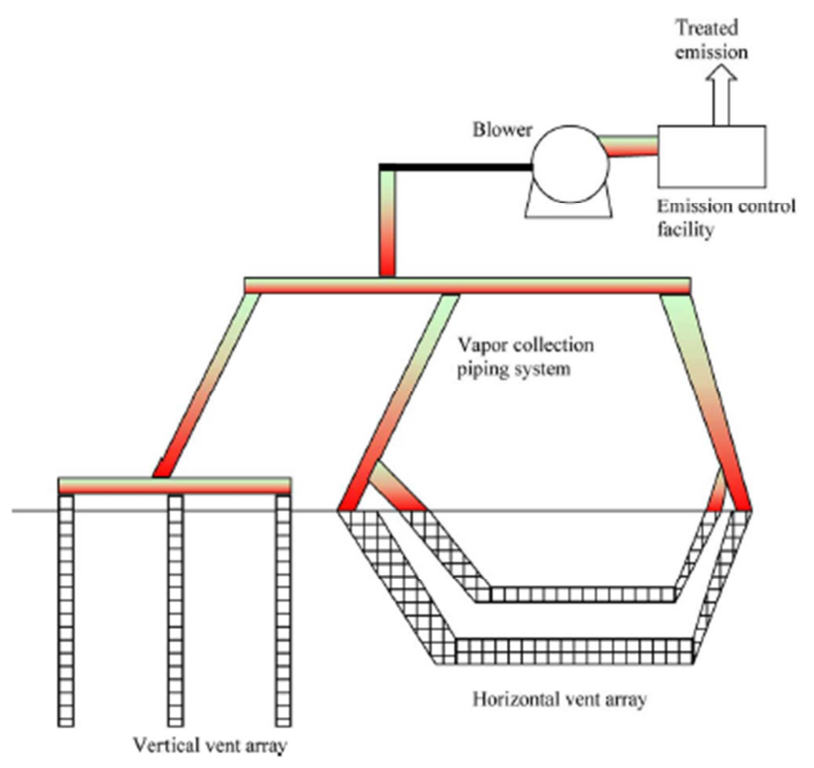

Figure 3. Bioventing Process [19].

Bioventing technique is more suitable for the production of different types of petroleum, mid-weight petroleum products like diesel tend to volatilize quickly and can be treated better with SVE, while the products more weight generally requires more time to biodegrade. The equipments used are easily available and has easy installation process. Short times require for this process ( 6 months to 2 years) and it can be combined easily with other technologies. This technique do not need to off-gas treatment.

Bioventing of contaminated soil limits application in low permeability and high clay content existing sites. It cannot always reach low cleanup limits and can be applied only for unsaturated soils but saturated zone cannot be treated.

\subsection{Landfarming}

Landframing is an above ground technology in which excavated contaminated soils spread on the ground surface in a thin layer (no more than $1.5 \mathrm{~m}$ ) for treatment (shown in figure 4) and stimulating aerobic microbial activity occurs in the contaminated soils through aeration and/or with the help of nutrients, minerals, and moisture content, reduces petroleum constituents [12, 32]. For the breaking of hydrocarbons and to accelerate the degradation process bacteria's added to the contaminated soil. Accelerated degradation of adsorbed petroleum products can be achieved by enhancing microbial activity. Proper mixing of the contaminated soil increases the interaction between the organics and microorganisms, helps to gain the required oxygen for aerobic biological degradation. If the degradation of petroleum contaminated soil high then more soil can be applied to the site which helps to replenish the supply of hydrocarbon and to maintain biological activity [12].

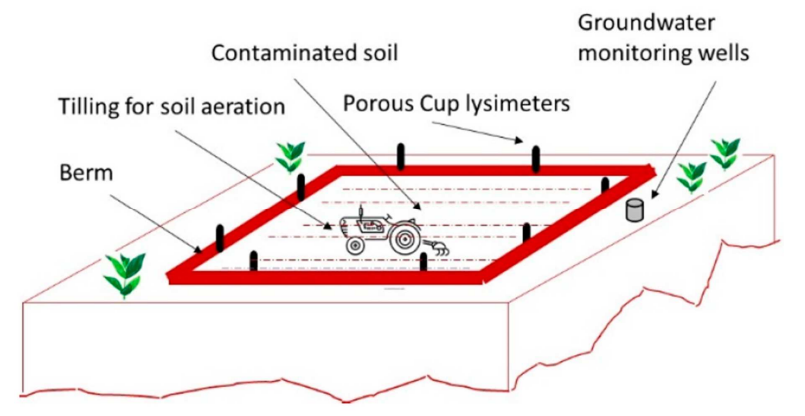

Figure 4. Typical landfarming system (adapted from [24]).

In landfarming technique large area of land is required and the contaminants can reach undisturbed site from the treatment site [12]. In this technique pre-treatment required for volatile contaminants because they can pollute air after volatilized into the atmosphere [10]. But heavier petroleum components cannot be degraded efficiently, less microbial growth and metabolic rates and temperature decrease the degradation of lighter petroleum constituents (optimum tem. $25-40^{\circ} \mathrm{C}$ ) cannot be treated with this technique. It is difficult to reduce constituent, which concentrations is less than 0.1 ppm and Concentration higher than 95\%. For soils of constituent concentrations of greater than 50,000 ppm TPH this method is not effective [32].

\subsection{Vitrification}

Vitrification is a technique of contaminant removal from soil, in which high temperature is used to 
stabilization/solidification soil into glassy matrix. Vitrification or molten glass is the process which melts soil or earthen materials and immobilized inorganics constituents and destroying organic pollutants by pyrolysis in high temperature $\left(1600-2000^{\circ} \mathrm{C}\right) \quad[10]$ (Figure 5). Organic constituents may produce gas at the time of heating. Vitrification is the technique which is applicable for both insitu and ex-situ. Vitrification method volatilized major percent of contaminants and rest portions are converted to chemically inert, crystalline product and stable glass. For the soil contaminated by very toxic and radioactive constituents this vitrification technique can be applied. But for the soils contaminated by high percent of organic matter or humidity, the vitrification technique cost much. The subsequent soil mainly can be used for agricultural [18]. Inorganics likeheavy metals and radionuclides are converted into strong, durable, and leaching resistant glass structure [10]. There are three classification of vitrification technique: Plasma processes: In which temperatures can be reached up to $5000^{\circ} \mathrm{C}$ via electrical discharges, electrical processes: Graphite electrodes are inserted for in-situ application of electrical energy into the soil [1] (Figure 5), thermal processes: Extra external heat source is needed and a typical reactor (refractory-lined rotary kit) [35].

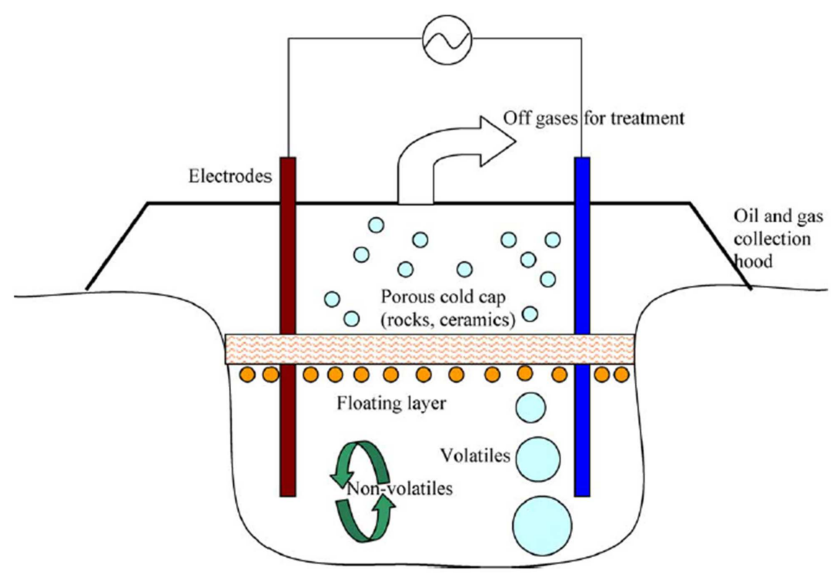

Figure 5. In situ vitrification system [11].

The contaminants depth may limit vitrification technique, and to ensure immobilization of the contaminants long-term monitoring is often needed. In vitrification technique high temperature requires to immobilize organic constituents and to demolish the constituents and certain contaminants are unsuited with these technique [10].

\subsection{Biodegradation and Phytoremediation}

Bioremediation is a technique for the remediation of contaminants from polluted soils by biological means likeplantation (shown in figure 6). This technique comprises of planting on the polluted soil to percolate the contaminants through the radical system of the plants and to collect in different parts (leaves, roots, stems etc.). This technique can break down and absorb hydrocarbons using bacterium (aerobic and anaerobic species). For the growth and development plants can consume essential heavy metals (Fe, $\mathrm{Mn}, \mathrm{Zn}, \mathrm{Cu}, \mathrm{Mg}$, Mo, and $\mathrm{Ni}$ ) [23] from soil or water. The mobility of several different metals in soil and the influence of the biodegradation process were observed. An agent cysteine is able to release some metals from contaminated soil and capacity of soil to retain metals is persuaded by the active microorganisms [14]. In Figure 6 is shown basic principle of phytoremediation. Bioremediation or phytoremediation can be classified into five basic categories [23]: (1) rhizofiltration, which is applied for water remediation where plant's roots are used to collect contaminants; (2) phytoextraction, which includes removal of pollutants from the soil; (3) phytotransformation, which can be applied to both soil and water and degrades contaminants through plant metabolism; (4) phytostimulation or plantassisted bioremediation, which works to stimulates microbial degradation by plant's root zone activities; and (5) phytostabilization, which reduce the relocation of contaminants through the soil medium by the plants. The effectiveness of biodegradation technique depends on the fact that when contaminate is devoted all the microbes die off. This technique is more effective in soil that maintains optimal moisture and $20^{\circ} \mathrm{C}$ of temperature and soils in colder climates (properly covered and insulated). Because this technique elapsed more time for clean-up time in the colder the ambient climate [13].

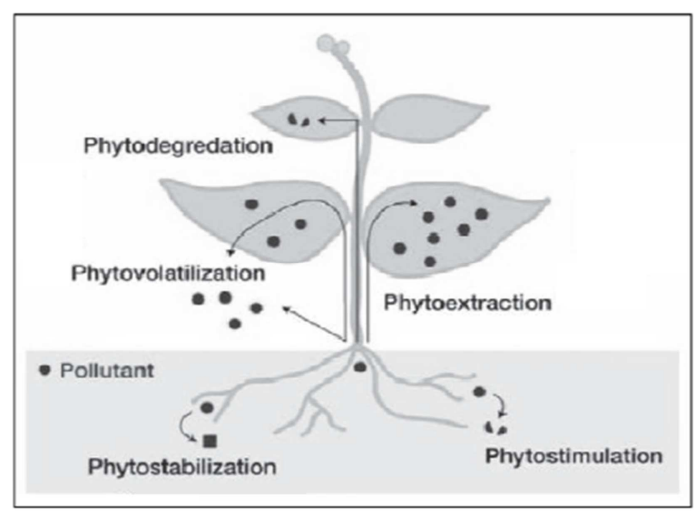

Figure 6. Basic scheme of pollutants Phytoremediation in soil [23].

It requires several cycle of culture to clean-up contaminants completely from a site and the disposal of contaminated, vegetation have to be in an appropriate manner [22]. This technique is advantageous to remove, collect, and/or degrade constituents of the soil and water environment by the plants. From the environment plants take away components, including nutrients, organics and heavy metals which may or may not be used in their function.

Phytoremediation/ biodegradation is an aesthetically pleasing, solar energy driven technique causes minimum site and environmental disturbance and it produce less secondary wastes to be treated. Large volume of contaminants can be treated and a conversion of organic pollutants to $\mathrm{CO}_{2}$ and water occurs rather than transferring toxicity. After the treatment the soil remains at the site and the top soil of the contaminated site can be utilize for agricultural purpose. This 
technique is more effective for the treatment of soils within 1 meter and groundwater within 3 meter from ground surface. This technique takes more than one growing season and bad climate and hydrologic conditions (flooding, drought) hampers the growth of plants. If animals eats the plants used in this technique, the contaminants may affect the food chain, the used plants should be disposed of in proper manner. For large contaminated sites this technique is cost-effective (low concentration of pollutants).

\section{Discussion}

Soil contamination is a matter of great concern all over the world that has different formation of pollutions. This study has been carried out to evaluate the efficiency different soil remediation techniques. It is important that, every remediation technique has some unique properties, advantages, disadvantages and limitations. All these are applicable for the removal of different /or same contaminants, but no technology can work to full fill all requirements [8]. An overview on the remediation technique is discussed here. Surface capping and encapsulation process confines the contaminants from being mixed with clean soil but cannot remove the contaminants completely. Soil stabilization process solidifies the soil and contaminant as well by some admixtures, and has less effect on environment also provides some strength to the soil. Bioventing process performs well for the soil containing light contaminants such as gasoline but not for heavier contaminants like oil. Besides that the equipment of bioventing process is readily available. Soil vaporextraction is a frequent applied technique with good result in short time and of low cost. But SVE process limits to apply in a clay and silt site polluted by landfill leachates that have volatile organic contaminants, heavy metals and other contaminants. In situ vitrification is an efficient complex hydrogeologic process, can remove various contaminants but cannot work properly in increased depth of soil and long monitoring is needed in this technique. Landfarming is an efficient and cost effective technology for TPH treatment. Landfarming process cleans the organic contaminants of landfill leachate but unable to clean inorganic contaminants, heavy metals. Soil washing process is an appropriate process for remediation soil contaminated by landfill leachates containing organic and inorganic contaminants and heavy metals. Phytoremediation is an increasing acceptance process for remediation of contaminants, has less disturbance of soil and use solar energy (available with increased temperature). This technique removes heavy metals $(\mathrm{Cd}, \mathrm{Cr}, \mathrm{Zn}, \mathrm{Hg}, \mathrm{Fe}, \mathrm{As}$ and $\mathrm{Pb})$, radio-nuclides, chlorinated solvents and petroleum hydrocarbon but it cannot work properly for the soil deeper than 1 meter, also this is a slow process and needs much time.

\section{Conclusions}

The author investigated that different technique is applicable for different contaminants removal and different site condition. In this study, it is found that any one technology is not well enough to purify soil in any contaminated area. So, to get better remediation two or more technique needs to be combined. Such as- landfarming process cleans the volatile organic compounds whereas soil vapor extraction process can clean inorganic volatile compounds of landfill leachates. Again, any technology which removes heavy metals can be combined with bioventing, any technology which removes only volatile organic compounds (like-soil washing) from soil can be combined with soil vapor extraction. As the selection of one or more remediation technologies depend on various factors, the decision making plays a very significant role on soil remediation and environmental system. In future research, more focus should be paid to soil remediation technique to evaluate the effectiveness and for establishing new in-situ remediation technologies.

\section{References}

[1] Acar, Y. B., Alshawabkeh, A., 1993. Principle of electrokinetic remediation. Journal of Environmental Science and Technology 27 (13), 2638-2647.

[2] Anderson, A., Mitchell, P., 2003. Treatment of mercurycontaminated soil, mine waste and sludge using silica microencapsulation. TMS Annual Meeting, Extraction and Processing Division, Mar 2-6 2003, San Diego, CA, pp. 265274.

[3] Barnes, D. L., 2003. Estimation of operation time for soil vapor extraction systems. Journal of Environmental Engineering 129 (9), 873-878.

[4] Bronze, O. E. New developments in hazardous materials research. Nova Science Publishers, N. Y., 2006. Environmental Protection Agency (EPA). Contaminants. Retrieved November 18, 2009, from Clean-Up Information: http://www.clu-in.org/contaminantfocus/

[5] Cascade, A. Deeper Look at Permeable Reactive Barriers. Available online: https://www.cascadeenv.com/resources/blogs/archive/a-deeper-look-at-permeablereactive-barriers/ (accessed on 4 September 2020).

[6] Conway R. A., Cordle S., Mercer J. W., Miller D. W., Rao P. S C. Overview. In: Ground Water and Soil Contamination Remediation: Toward Compatible Science, Policy, and Public Perception. Report on Colloquium Sponsored by the Water Science and Technology Board. Colloquium 5 of a Series, National Academy Press, Washington, D.C., 1990, p. 1-16.

[7] Druss, D. L., 2003. Guidelines for Design and Installation of Soil-Cement Stabilization, Geotechnical Special Publication, Feb 10-12 2003, New Orleans, LA, Number 120, pp. 527-539.

[8] Dunea D, Iordache S, Pohoata A, Frasin LBN (2014) Investigation and selection of remediation technologies for petroleum-contaminated soils using a decision support system. Water Air Soil Pollut 225: 1-18.

[9] Emerging Technologies for the Remediation of Metals in Soils Electrokinetics. Technology Overview. Interstate Technology and Regulatory Cooperation Work Group. December, 1997, 19 p. 
[10] FRTR, (1999). Soil flushing. Federal Remediation Technologies Roundtables, USEPA, Washington, DC.

[11] F. I. Khan, T. Husain, R. Hejazi. (2004). An overview and analysis of site remediationtechnologies. Journal of Environmental Management. Vol. 71, 95-122.

[12] Hejazi, R. F., 2002. Oily Sludge Degradation Study Under Arid Conditions Using a Combination of Landfarm and Bioreactor Technologies. PhD thesis, Faculty of Engineering and Applied Science, Memorial University of Newfoundland, St John's, Canada.

[13] K. T. Jarvinen, E. S. Melin, and J. A. Puhakka. (1994). Highrate bioremediation of chlorophenol contaminated groundwater at low temperatures. Environmental Science \& Technology. Vol. 28, 2387-2392.

[14] K. W. Tsang, P. R. Dugan, R. M. Pfister. (1994). Mobilization of $\mathrm{Bi}, \mathrm{Cd}, \mathrm{Pb}, \mathrm{Th}$, and $\mathrm{U}$ ions from contaminated soil and the influence of bacteria on the process. In: Emerging Technologies in Hazardous Waste Management IV. Washington, DC: American Chemical Society.

[15] Lin, H. K., Man, X. D., Walsh, D. E., 2001. Lead removal via soil washing and leaching. JOM 53 (12), 22-25.

[16] Liu Y, Zeng G, Zhong H, Wang Z, Liu Z, Cheng M, Liu G, Yang X, Liu S (2017). Effect of rhamnolipid solubilization on hexadecane bioavailability: enhancement or reduction? JHazard Mater 322: 394-401.

[17] Meagher, R. B. (2000). "Phytoremediation of toxic elemental and organic pollutants." Curr. Opin. Plant Biol., 3, 153-162.

[18] Meuser H (2013) Soil remediation and rehabilitation: treatment of contaminated and disturbed land. Springer, Dordrecht.

[19] Mihopoulos F. I. Khan et al., 2004. An overview and analysis of site remediation technologies. Journal of Environmental Management 71 (2004) 95-122.

[20] Mitchell, E. D. and Thomas, W. E. (2012). In- situ thermal remediation. Technical Guidance Document, Indiana Department of Environmental Management: 1-9.

[21] Mohammad, I. L., Zhen, L., Peter, J. S. and Xiao, Y. (2008). Phytoremediation of heavy metals polluted soil and water: progresses and perspectives. Journal of Zhejiang University, 9 (3): $210-220$

[22] Mulligan, C. N., Yong, R. N., and Gibbs, B. F. (2001). "Remediation technologies for metal-contaminated soils and groundwater: an evaluation." Eng. Geol. (Amsterdam), 60, 193-207.
[23] O. Schacht, K. Ajibo. (2002). Soil Bioremediation: In-Situ vs. Ex-situ. (Costs, Benefits, and Effects). WSP and Göteborg Energi.

[24] Pavel, L.; Gavrilescu, M. (2008). Overview of ex situ decontamination techniques for soil cleanup. Environ. Eng. Manag. J. 7, 815-834.

[25] Paulo, J. C., Favas, J. P., Mayank, V., Rohan, D. and Manoj, S. R. (2014). Phytoremediation of soil contaminated with metals and metalloids at mining areas: Potential of Native Flora. INTECH Open Science: 486-515. http://dx.doi.org/10.5772/57469.

[26] Raphl, S. B., John, C. L. and Gorm, H. (2006). Application of thermal remdiation techniques for in situ treatment of contaminated soil and water. NATO Advanced Research Workshop, Athen, Greece.

[27] Raymond, A. W. and Felix, O. (2011). Heavy metals in contaminated soil: A review of sources, chemistry, risk and best available strategies for remediation. International Scholar Research. http://dx.org 10.5402/ 2011 /4 02647.

[28] Reddy KR, Yaghoubi P, Yukselen-Aksoy Y (2015). Effects of biochar amendment on geotechnical properties of landfill cover soil. Waste Manag Res 33 (6): 524-532.

[29] Suthersan, S. S. (1999). In situ air sparging. Remediation engineering, CRC Press.

[30] USEPA (1995). How to evaluate alternative clean up technologies for underground storage tank sites. Office of Solid Waste and Emergency Response. EPA 510 - B - 95-007, Washington, DC.

[31] USEPA (1996). In situ soil vapour - extraction. Office of Solid Waste and Emergency Response, Washington, DC.

[32] USEPA (1998). Soil vapour extraction. Office of the underground storage tank, EPA 510 - B - 95-007.

[33] USEPA (2006). In Situ Treatment Technologies for Contaminated Soil, Solid Waste and Emergency Response. EPA 542/F- 06/013.

[34] USEPA (2012). A Citizen's Guide to Thermal Desorption Office of Solid Waste and Emergency Response-EPA 542-F12-020. www.epa.gov/superfund/sites. Accessed 2 June 2018.

[35] Wait, S. T., Thomas, D., (2003). The Characterization of Base Oil Recovered From the Low Temperature Thermal Desorption of Drill Cuttings, SPE/EPA Exploration and Production Environmental Conference, Mar 10-12, San Antonio, TX, pp. 151-158. 